09

\title{
Люминесцентные свойства боросиликатного стекла, легированного церием
}

\author{
(C) Д.Т. Валиев ${ }^{1}$, C.A. Степанов ${ }^{1}$, G. Yao ${ }^{2}$, Y. Zhou $^{2}$ \\ ${ }^{1}$ Национальный исследовательский Томский политехнический университет, \\ Томск, Россия \\ ${ }^{2}$ Changchun University of Science and Technology, \\ Changchun, China \\ E-mail: dtdamirka@gmail.com
}

Поступила в Редакцию 6 мая 2019 г.

В окончательной редакции 6 мая 2019 г.

Принята к публикации 14 мая 2019 г.

ABS-BGP $\left(\mathrm{Al}_{2} \mathrm{O}_{3}-\mathrm{B}_{2} \mathrm{O}_{3}-\mathrm{SiO}_{2}-\mathrm{BaCO}_{3}-\mathrm{Gd}_{2} \mathrm{O}_{3}-\mathrm{P}_{2} \mathrm{O}_{5}\right)$ стекла, допированные различными концентрациями $\mathrm{Ce}^{3+}$ были синтезированы методом высокотемпературного плавления. Исследованы оптические, структурные и люминесцентные свойства. Было зафиксировано излучение в спектральной области $350-550 \mathrm{~nm}$, связанное с переходами ионов $\mathrm{Ce}^{3+}$. Кинетика затухания люминесценции характеризуется двумя компонентами. Быстрая компонента затухания составляет 45-90 ns. Для медленной компоненты показано уменьшение времени затухания с 4 до $0.9 \mu \mathrm{s}$ с увеличением концентрации ионов церия. По результатам изучения спектров люминесценции сделано предположение о существовании различных излучающих состояний иона $\mathrm{Ce}^{3+}$ в боросиликатном стекле.

Ключевые слова: сцинтилляционные стекла, люминесцентные свойства, кинетика затухания люминесценции.

DOI: 10.21883/FTT.2019.10.48264.473

\section{1. Введение}

Расширение сферы применения ионизирующих излучений, включая медицинскую диагностику и терапию, системы радиационного неразрушающего контроля, атомную энергетику определяет потребность в материалах для детектирования ионизирующего излучения, совершенствования их свойств, увеличения чувствительности, быстродействия, разрешающей способности, разработки новых материалов с заданными характеристиками [1-3].

Стекла, активированные редкоземельными ионами (РЗИ) могут служить альтернативой сцинтилляционным кристаллам, т.к. обладают интенсивной люминесценцией, хорошей растворимостью для РЗИ, возможностью модификации физико-химических свойств в широком диапазоне за счет изменения состава стеклообразующих компонент, относительно низкой стоимостью и др. [4-6]. Основной проблемой является более низкий световой выход люминесцирующих стекол по сравнению с кристаллами. Эффективность сцинтилляционного процесса напрямую связана с механизмами диссипации поглощенной энергии в материале. Процессы безызлучательной передачи энергии между ионами-активаторами, между матрицей и активатором, а также закономерности релаксации возбужденного состояния определяют основные характеристики сцинтилляционных материалов [7].

Люминесцентное стекло, активированное ионами $\mathrm{Ce}^{3+}$, является перспективным материалом для создания дозиметров, сцинтилляторов, используемых в та- ких областях как физика высоких энергий и рентгенография. Боросиликатные стекла обладают хорошими физико-химическими и эксплуатационными свойствами, имеют достаточно низкую температуру плавления и являются негигроскопичными, что делает их еще более интересными для изучения [8-13]. Однако на данный момент люминесцентные стекла, активированные РЗИ, имеют низкую световую отдачу по сравнению с монокристаллами. Выбор состава матрицы стекла важен в этом случае и может быть эффективным подходом для повышения интенсивности люминесценции стекла. Разработка оптимальных составов стекол, подбор катионовмодификаторов с целью улучшения физико-химических свойств стекла также представляют немаловажную задачу [14-15].

В настоящее время практически отсутствует информация о процессах, проходящих в боросиликатных стеклах при воздействии коротких импульсов ионизирующего излучения. Использование импульсных электронных пучков наносекундной длительной и времяразрешенной спектроскопии в этом случае является одним из наиболее важных и информативных инструментов для изучения люминесцентных процессов в неорганических стеклах.

Целью данной работы является решение двух основных взаимосвязанных задач: 1) изготовить люминесцентное стекло сложного состава ABS-BGP $\left(\mathrm{Al}_{2} \mathrm{O}_{3}-\mathrm{B}_{2} \mathrm{O}_{3}-\mathrm{SiO}_{2}-\mathrm{BaCO}_{3}-\mathrm{Gd}_{2} \mathrm{O}_{3}-\mathrm{P}_{2} \mathrm{O}_{5}\right)$, активированное ионами $\mathrm{Ce}^{3+}$ методом высокотемпературного плавления и 2) провести сравнительный анализ катодо- 
Таблица 1. Состав изготовленных боросиликатных стекол

\begin{tabular}{c|c|c|c|c|c|c|c|c|c|}
\hline \multirow{2}{*}{ Стекло } & \multicolumn{7}{c|}{ Состав (mol.\%) } & \multirow{2}{*}{$\rho, \mathrm{g} / \mathrm{cm}^{3}$} \\
\cline { 2 - 10 } & $\mathrm{SiO}_{2}$ & $\mathrm{~B}_{2} \mathrm{O}_{3}$ & $\mathrm{BaCO}_{3}$ & $\mathrm{Al}_{2} \mathrm{O}_{3}$ & $\mathrm{Gd}_{2} \mathrm{O}_{3}$ & $\mathrm{P}_{2} \mathrm{O}_{5}$ & $\mathrm{Sb}_{2} \mathrm{O}_{3}$ & $\mathrm{Ce}_{2} \mathrm{O}_{3}$ & \\
\hline ABS-BGP & 30.5 & 24 & 3 & 9 & 30 & 3 & 0.5 & 0 & 4.529 \\
ABS-BGP:Ce0.1 & 30.4 & 24 & 3 & 9 & 30 & 3 & 0.5 & 0.1 & 4.540 \\
ABS-BGP:Ce0.2 & 30.3 & 24 & 3 & 9 & 30 & 3 & 0.5 & 0.2 & 4.591 \\
ABS-BGP:Ce0.3 & 30.2 & 24 & 3 & 9 & 30 & 3 & 0.5 & 0.3 & 4.708 \\
ABS-BGP:Ce0.4 & 30.1 & 24 & 3 & 9 & 30 & 3 & 0.5 & 0.4 & 4.71
\end{tabular}

люминесцентных свойств синтезированных стекол. Кроме того, обсуждается влияние различной концентрации ионов $\mathrm{Ce}^{3+}$ на люминесцентные свойства и время затухания люминесценции.

\section{2. Образцы и методика эксперимента}

Стекло ABS-BGP готовили методом высокотемпературного плавления. Номинальные составы экспериментальных стекол перечислены в табл. 1. Исходными материалами были реагенты $\mathrm{Al}_{2} \mathrm{O}_{3}, \mathrm{H}_{3} \mathrm{BO}_{3}, \mathrm{SiO}_{2}, \mathrm{BaCO}_{3}$, $\mathrm{Gd}_{2} \mathrm{O}_{3}, \mathrm{P}_{2} \mathrm{O}_{5}, \mathrm{Ce}_{2} \mathrm{O}_{3}, \mathrm{~Tb}_{2} \mathrm{O}_{3}$ и $\mathrm{Sb}_{2} \mathrm{O}_{3}$. Сырье было номинально чистым. Соответствующие количества этих материалов смешивали в агатовой ступе; смешанные материалы плавили при температуре $1450^{\circ} \mathrm{C}$ в течение 120 min в корундовом тигле в муфельной печи. После плавления расплав выливали в предварительно разогретую форму из нержавеющей стали и отжигали при температуре $650^{\circ} \mathrm{C}$ в течение $2 \mathrm{~h}$, чтобы снять внутреннее напряжение, а затем охлаждали до комнатной температуры. После резки, шлифовки и полировки были получены образцы стекла толщиной $2 \pm 0.02 \mathrm{~mm}$.

Плотность стекла измеряли по методу, основанному на законе Архимеда.

Рентгенофазовый анализ (РФА) стекла осуществлялся на дифрактометре XRD-7000S (Shimadzu, Япония). Спектры оптического пропускания стекол измерялись на спектрофотометре Lomo-Photonics SF-256 UVI в спектральном диапазоне 200-800 nm. Измерение фотолюминесценции и фотовозбуждения стекол проводили при комнатной температуре с помощью спектрофлуориметра Agilent Cary Eclipse с использованием Хе лампы $150 \mathrm{~W}$ в качестве источника возбуждения (спектральный диапазон 190-1100 nm).

Для возбуждения импульсной катодолюминесценции использовался ускоритель электронов типа GIN-600 с вакуумным диодом. Длительность электронного импульса на полуширине составляла $10 \mathrm{~ns}$, средняя энергия ускоренных электронов составляла $250 \mathrm{keV}$. Образцы стекол помещали в вакуумную камеру. Плотность энергии возбуждения варьировалась от 6 до $300 \mathrm{~mJ} / \mathrm{cm}^{2}$. Кинетику затухания люминесценции регистрировали с помощью фотоумножителя ФЭУ-97 с использованием монохроматора МДР-23 (спектральный диапазон
200-2000 nm, линейная дисперсия $1.3 \mathrm{~nm} / \mathrm{mm}$ ) и цифрового осциллографа Tektronix DPO3034 (300 MHz). Спектр излучения был исправлен на спектральную чувствительность оптического тракта.

\section{3. Результаты и обсуждение}

Проведенный РФА (рис. 1,a) подтвердил аморфную природу синтезированных стекол и не дает никаких доказательств разделения или осаждение любой кристаллической фазы во время процессов плавления и отжига с увеличением содержания $\mathrm{CeO}_{2}$ до $0.4 \mathrm{~mol} . \%$.

Спектры пропускания образцов стекла показаны на рис. $1, b$. С увеличением концентрации ионов $\mathrm{Ce}^{3+}$ край собственного поглощения смещается в длинноволновую область спектра. Аналогичный эффект для аморфных матриц переменного состава шихты с увеличением концентрации церия наблюдался в работах $[16,17]$. Этот эффект чаще всего связан с увеличением концентрации ионов $\mathrm{Ce}^{4+}$. В работе [18] показано взаимное положение полос поглощения ионов $\mathrm{Ce}^{3+}$ и $\mathrm{Ce}^{4+}$ в кремниевой аморфной матрице. Отмечается, что положение полосы поглощения иона $\mathrm{Ce}^{3+}$ может несколько меняться. Вместе с тем, положение широкой полосы поглощения иона $\mathrm{Ce}^{4+}$ с максимумом около $240 \mathrm{~nm}$ остается относительно постоянным. Положение и ширина данной полосы поглощения объясняется переносом заряда от иона $\mathrm{O}^{2-}$ к иону $\mathrm{Ce}^{4+}[18-20]$.

Спектры возбуждения и излучения образцов ABS-BGP: $\mathrm{Ce}^{3+}$ показаны на рис. $1, c$. Пики эмиссии и возбуждения, наблюдаемые при 380 и $325 \mathrm{~nm}$, вызваны возбуждением $4 f-5 d$ с последующим излучением $5 d-4 f$ ионов $\mathrm{Ce}^{3+}$.

Полоса излучения иона $\mathrm{Ce}^{3+}$ состоит из широкой полосы с максимумом при $380 \mathrm{~nm}$ при длинах волн возбуждения $325 \mathrm{~nm}$, что способствует переходам с самого низкого уровня $5 d$ на спин-орбитальное разделение ${ }^{2} F_{5 / 2}$ и ${ }^{2} F_{7 / 2}$ состояний ${ }^{4} f_{1}$ конфигурации [21,22]. Спектры излучения всех образцов стекла подобны.

Были детально изучены катодолюминесцентные спектры, и кинетика затухания люминесценции стекла ABS-BGP, легированного $\mathrm{Ce}^{3+}$ в наносекундном временном интервале (рис. 2). При импульсном электронном возбуждении исследуемого стекла наблюдалась 

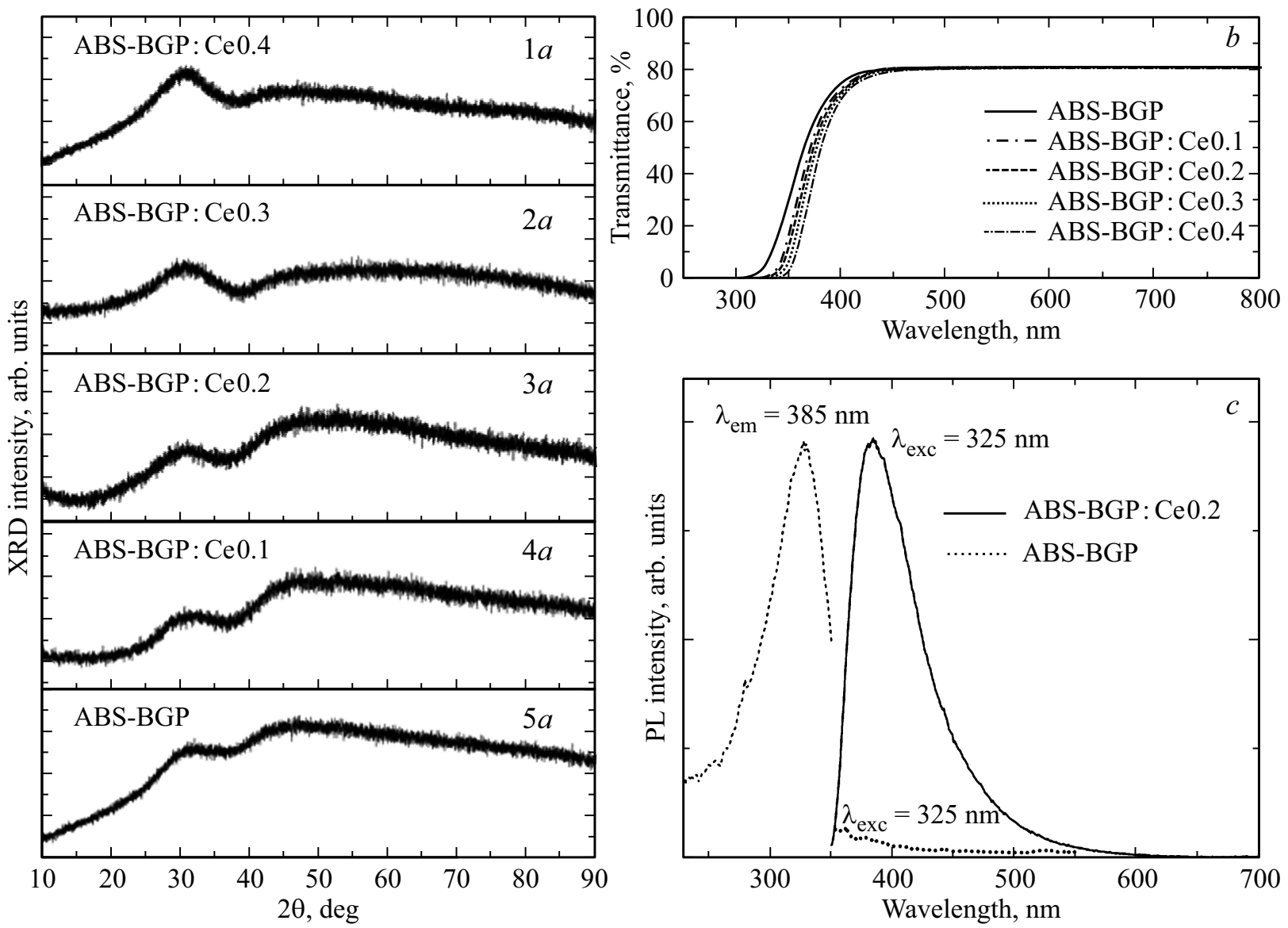

Рис. 1. РФА: $(a)$ - спектры оптического пропускания, $(b)-$ спектры фотовозбуждения и фотолюминесценции, $(c)-\mathrm{ABS}-\mathrm{BGP}$ стекол с различным содержанием церия.

интенсивная широкозонная люминесценция с пиком излучения при $385 \mathrm{~nm}$. В работе [23] было продемонстрировано, что длина волны $5 d-4 f$ переходов ионов $\mathrm{Ce}^{3+}$ широко варьируется от ближней ультрафиолетовой до красной области спектра. Связывают данное явление с расщеплением кристаллического поля $5 d$ конфигурации в результате взаимодействия с материалом стеклянной матрицы. Основные процессы при возбуждении импульсом электронов можно разделить на три этапа: первый - это взаимодействие электронов высокой энергии с материалом стекла, которое может обеспечить процесс ионизации. Второй этап связан с переносом некоторой доли возбужденных электронов и дырок к центру люминесценции и, наконец, с процессом люминесценции [24,25]. В этом случае может происходить прямой переход из валентной зоны в зону проводимости с релаксацией без излучения к центру люминесценции ионов $\mathrm{Ce}^{3+}$. Для детального рассмотрения данного излучения спектр был разложен на Гауссианы. В результате получены 6 полос $A 1-A 6$ (табл. 2).

Подобный сложный спектральный состав люминесценции в наносекундном временном интервале может объясняться наличием нескольких излучательных центров ионов $\mathrm{Ce}^{3+}$. Сообщалось о существовании, по край-

Таблица 2. Положение максимума, полуширина полосы и вклад полосы излучения

\begin{tabular}{c|c|c|c|c|c|c}
\hline \multirow{2}{*}{ Параметры } & \multirow{2}{*}{$E_{h v \text { max }}(\mathrm{eV})$} & \multirow{2}{*}{ FWHM $(\mathrm{eV})$} & \multicolumn{4}{|c}{ Вклад полосы излучения } \\
\cline { 4 - 7 } & & & ABS-BGP:Ce0.4 & ABS-BGP:Ce0.3 & ABS-BGP:Ce0.2 & ABS-BGP:Ce0.1 \\
\hline$A 1$ & 2.48 & 0.32 & 0.045 & 0.045 & 0.033 & 0.018 \\
$A 2$ & 2.81 & 0.26 & 0.116 & 0.118 & 0.119 & 0.037 \\
$A 3$ & 3.04 & 0.26 & 0.216 & 0.175 & 0.156 & 0.094 \\
$A 4$ & 3.27 & 0.26 & 0.319 & 0.337 & 0.108 & 0.153 \\
$A 5$ & 3.52 & 0.26 & 0.233 & 0.152 & 0.075 & 0.078 \\
$A 6$ & 3.74 & 0.32 & 0.071 & 0.068 &
\end{tabular}



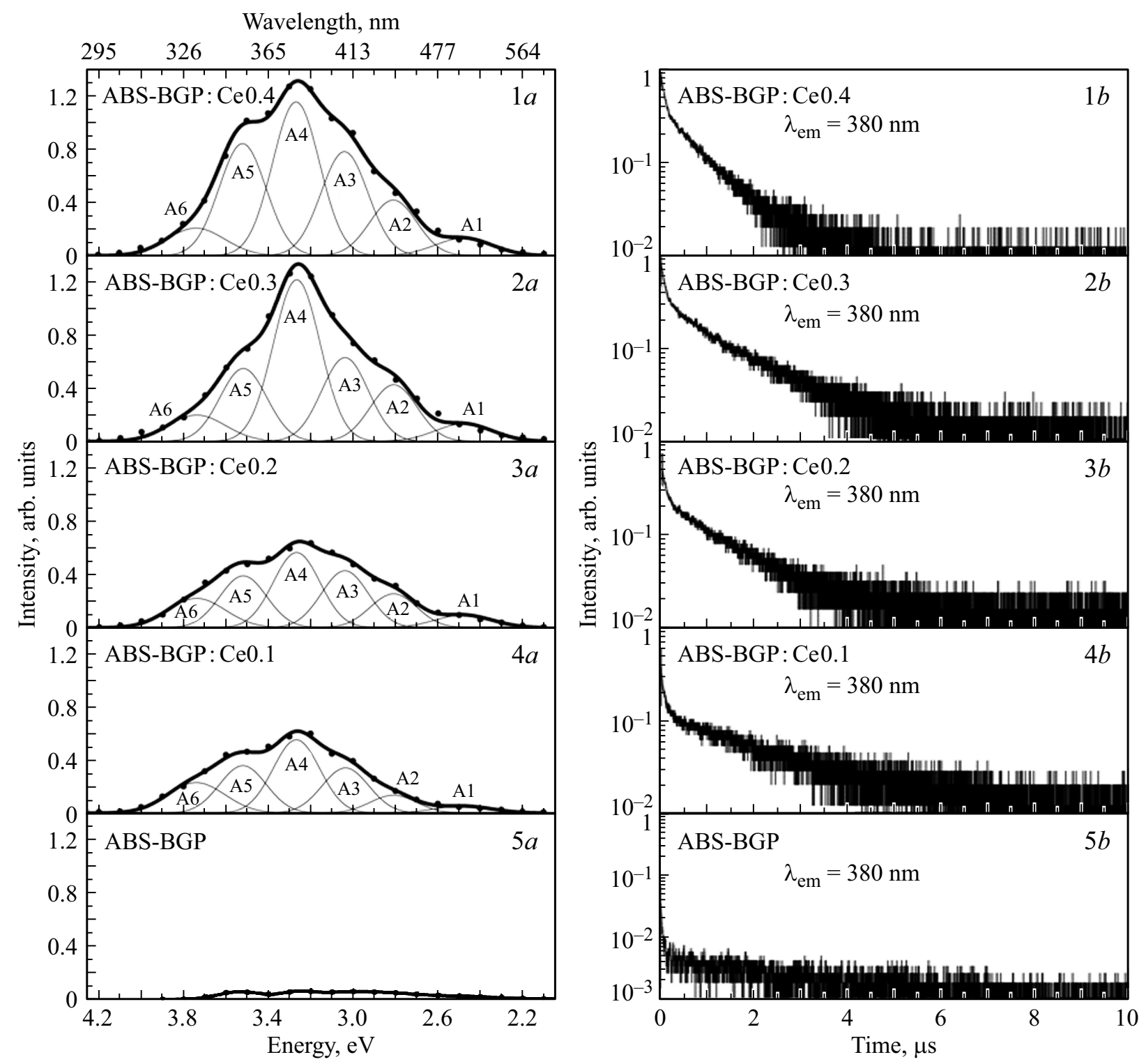

Рис. 2. Спектры импульсной катодолюминесценции (a.1-5) и кинетические кривые затухания люминесценции (b.1-5) ABS-BGP стекол с различным содержанием церия.

ней мере, двух различных излучательных центров ионов $\mathrm{Ce}^{3+}$ в оксифторборататном стекле. Каждый из таких центров отвечает не более чем за два излучающих перехода [26,27]. В нашем случае мы связываем с ионами церия переходы $A 1-A 5$ [23-28]. Природа полосы излучения $A 6$ не ясна. Возможно полоса излучения $A 6$ связана с процессами взаимодействия церия и материала аморфной матрицы, однако данные вопросы требуют дальнейшего изучения.
Кинетика затухания люминесценции в наносекундном временном интервале может быть связана с ионами церия и аппроксимирована суммой двух экспоненциальных функций. „Быстрая“ составляющая затухания $\tau_{1}$ увеличивается с 45 до $90 \mathrm{~ns}$, а „медленная“ составляющая $\tau_{2}$ уменьшается с $4 \mu \mathrm{s}$ до $0.9 \mu \mathrm{s}$ с ростом концентрации ионов церия (рис. 2, b. 1-5, табл. 3). Характер „медленной“ составляющей может быть связан с излучением материала аморфной матрицы.

Таблица 3. Характеристические времена затухания люминесценции на длине волны излучения $380 \mathrm{~nm}$

\begin{tabular}{c|c|c|c|c|c}
\hline Параметры & ABS-BGP & ABS-BGP:Ce0.1 & ABS-BGP:Ce0.2 & ABS-BGP:Ce0.3 & ABS-BGP:Ce0.4 \\
\hline$\tau_{1}, \mathrm{~ns}$ & $45 \pm 5$ & $70 \pm 5$ & $90 \pm 5$ & $90 \pm 5$ & $90 \pm 5$ \\
$\tau_{2}, \mu \mathrm{s}$ & $4 \pm 0.2$ & $2.3 \pm 0.2$ & $1.3 \pm 0.2$ & $1.3 \pm 0.2$ & $0.9 \pm 0.2$
\end{tabular}




\section{4. Заключение}

Сцинтилляционные стекла ABS-BGP $\left(\mathrm{Al}_{2} \mathrm{O}_{3}-\mathrm{B}_{2} \mathrm{O}_{3}-\right.$ $\left.\mathrm{SiO}_{2}-\mathrm{BaCO}_{3}-\mathrm{Gd}_{2} \mathrm{O}_{3}-\mathrm{P}_{2} \mathrm{O}_{5}\right)$, легированные различными концентрациями $\mathrm{Ce}^{3+}$, были получены методом высокотемпературного плавления. Интенсивность люминесценции постепенно возрастает с увеличением легирующих ионов $\mathrm{Ce}^{3+}$ в диапазоне от 0.1 до $0.4 \mathrm{~mol} \%$. Показано, что спектр излучения может быть описан суммой шести полос Гауссовой формы. Полосы излучения на 2.48 , $2.81,3.04,3.27,3.52 \mathrm{eV}$ можно связать с излучением иона церия - рост концентрации церия коррелирует с ростом интенсивности данных полос (табл. 2). Полоса на $3.74 \mathrm{eV}$ проявляется только в присутствие церия, но ее вклад остается постоянным. По всей видимости, данную полосу свечения можно отнести к процессам в данной стеклянной матрице в присутствие церия.

Кинетика затухания люминесценции в наносекундном временном интервале может быть аппроксимирована суммой двух экспоненциальных функций. „Быстрая“ и „медленная“ составляющая изменяются с ростом концентрации церия. „Медленная“ составляющая, связанная с излучением стеклянной матрицы, уменьшается с $4 \mu \mathrm{s}$ до $0.9 \mu$ s при увеличении концентрации церия. Конфликт интересов: авторы заявляют об отсутствии конфликта интересов.

\section{Финансирование работы}

Эксперименты проводились в рамках реализации программы развития Национального исследовательского Томского политехнического университета среди ведущих университетов мира 5-100.

\section{Список литературы}

[1] T. Yanagida, Opt. Mater. 35, 1987 (2013).

[2] M. Nikl, A. Yoshikawa. Adv. Opt. Mater. 3, 463 (2015).

[3] P. Lecoq, A. Annenkov, A. Gektin, M. Korzhik, C. Pedrini. Springer-Verlag (2006). $251 \mathrm{p}$.

[4] G. Okada, S. Vahedi, B. Morrell, C. Koughia, G. Belev, T. Wysokinski, D. Chapman, C. Varoy, A. Edgar, S. Kasap. Opt. Mater. 35, 1976 (2013).

[5] F. Zaman, G. Rooh, N. Srisittipokakun, H.J. Kim, E. Kaewnuam, P. Meejitpaisan, J. Kaewkhao. Rad. Phys. Chem. 130, 158 (2016).

[6] E.F. Polisadova, D.T. Valiev, K.N. Belikov, N.L. Egorova. Glass Phys. Chem. 41, 1, 98 (2015)

[7] J. Pisarska, A. Kos, M. Soltys, L. Zur, W. Pisarski. J. NonCryst. Solids 88, 1 (2014).

[8] S. Baccaro, R. Dall'Igna, P. Fabeni, M. Martini, J.A. Mares, F. Meinardi, M. Nikl, K. Nitsch, G.P. Pazzi, P. Polato, C. Susini, A. Vedda, G. Zanella, R. Zannoni. J. Lumin. 673, 87 (2000).

[9] H. Luo, X. Hu, W. Liu, Y. Zhang, A. Lu, X. Hao. J. Non-Cryst. Solids 389, 86 (2014).

[10] Z. Zhu, Y. Zhang, Y. Qiao, D. Liu, B. Wang, Z. Zhang. J. NonCryst. Solids 358, 1550 (2012).
[11] K. Annapurna, R. N. Dwivedi, P. Kundu, S. Buddhudu. Mater. Lett. 58, 787 (2004).

[12] Carel W.E. van Eijk. Rad. Meas. 38, 337 (2004).

[13] Y. Fujimoto, T. Yanagida, S. Wakahara, S. Suzuki, S. Kurosawa, A. Yoshikawa. Rad. Meas. 55, 124 (2013).

[14] L.H. Huang, X.J. Wang, H. Lin, X.R. Liu. J. Alloys Compd. 316, 256 (2001).

[15] X.Y. Sun, D.G. Jiang, W.F. Wang, C.Y. Cao, Y.N. Li, G.T. Zhen, H. Wang, X.X. Yang, H.H. Chen, Z.J. Zhang, J.T. Zhao. Nucl. Inst. Meth. Phys. Res. A 716, 90 (2013).

[16] C. Zuo, A. Lu, L. Zhu. Mater. Sci. Eng. B 175, 229 (2010).

[17] Y. Chen, D. Luo, L. Luo, X. Wang, T. Tang, W. Luo. J. NonCryst. Solids 386, 124 (2014).

[18] M.-L. Brandily-Anne, J. Lumeau, L. Glebova, L. Glebov, J of Non-Cryst. Solids 356, 2337 (2010).

[19] R. Reisfeld, H. Minti, A. Patra, D. Ganguli, M. Gaft. Spectrochim. Acta A 54, 2143 (1998).

[20] A. Sontakke, J. Ueda, Y. Katayama, Y. Zhuang, P. Dorenbos, S. Tanabe. J. Appl. Phys. 117, 013105 (2015).

[21] J. Sun, Z. Zhao. Mater. Lett. 165, 63 (2016).

[22] L.H. Zheng, X.Y. Sun, R.H. Mao, H.H. Chen, Z.J. Zhang, J.T. Zhao. J. Non Cryst. Solids 403, 1 (2014).

[23] P. Dorenbos. J. Lumin. 135, 93 (2013).

[24] T. Coenen, N.M. Haegel. Appl. Phys. Rev. 4, 031103 (2017).

[25] M. Nikl. Meas. Sci. Technol. 17, R37 (2006).

[26] J. Tang, W. Zhou, J. Yang, J. Wang, Y. Li, X. Kuang, H. Liang. Opt. Exp. 20, A510 (2012).

[27] A. Bahadur, Y. Dwivedi, S.B. Rai. Spectrochim. Acta. A 110, 400 (2013).

[28] C. Canevali, M. Mattoni, F. Morazzoni, R. Scotti, M. Casu, A. Musinu, R. Krsmanovic, S. Polizzi, A. Speghini, M. Bettinelli. J. Am. Chem. Soc. 127, 14681 (2005).

Редактор Т.Н. Василевская 